\title{
An unknown Roman bridge on sangarius and ancient road system around it
}

Refik Arıkan*,

Suggested Citation:

, Global Journal

on Humanites \& Social Sciences.

ABSTRACT

E-mail address: 


\section{Introduction}




\section{Road System Around The Bridge}




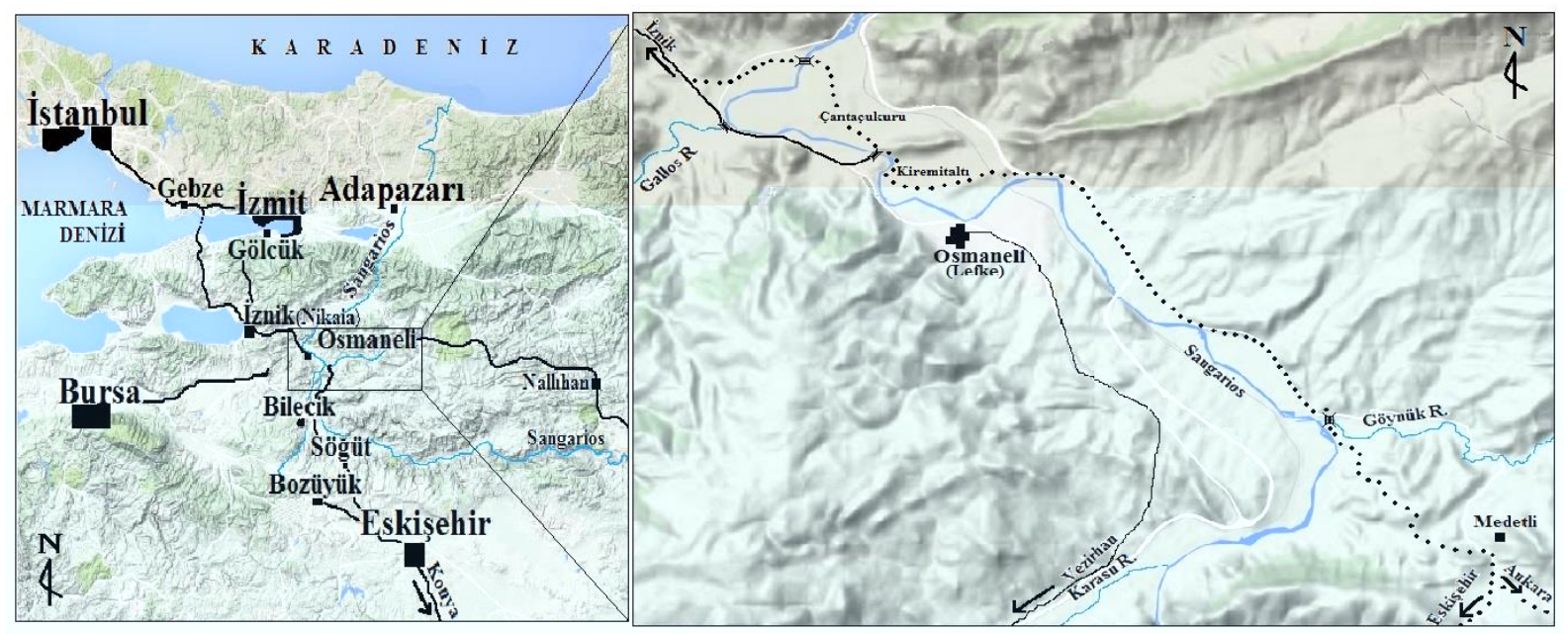


3. Property of the Bridge 


\section{Conclusion}

\section{Reference}




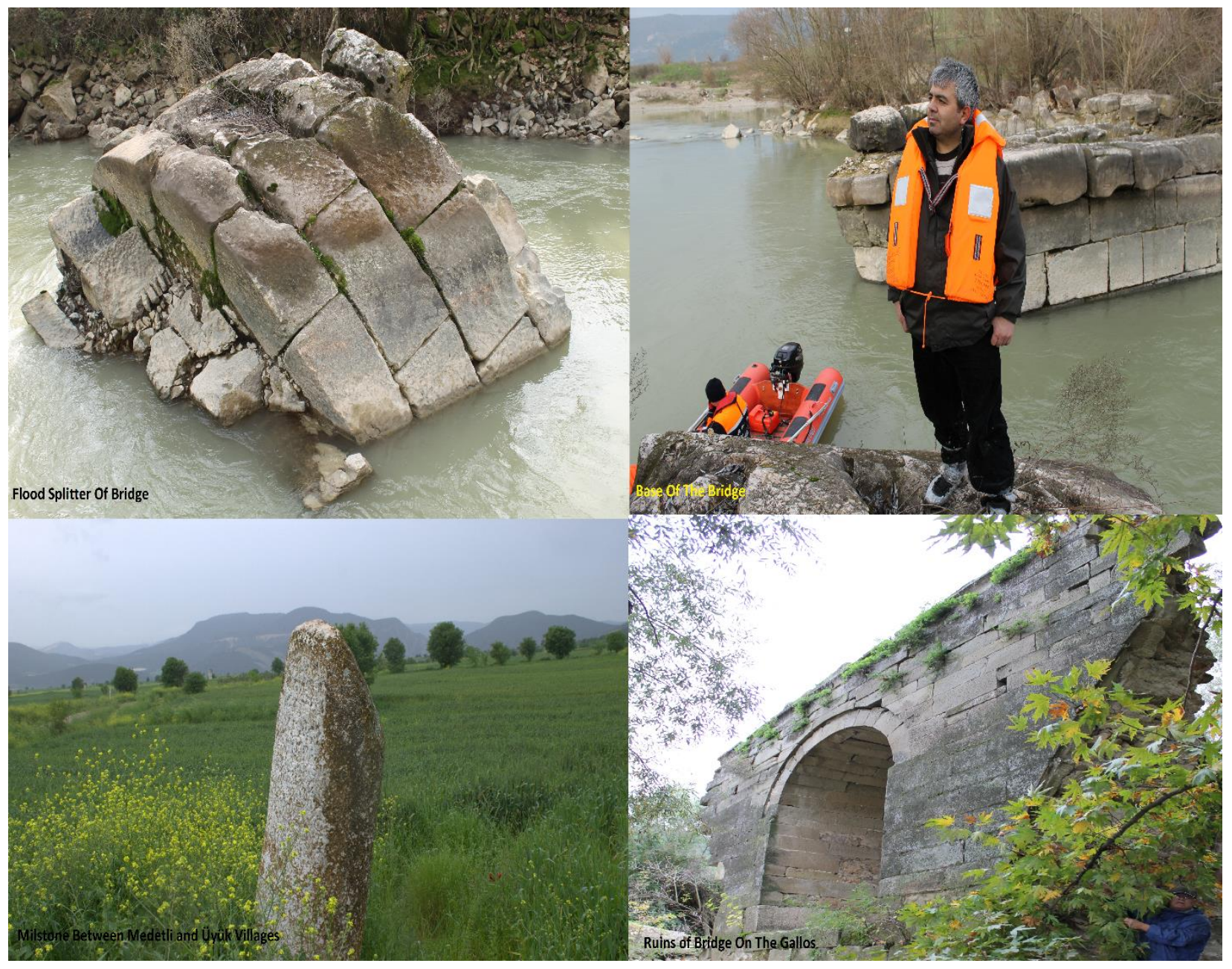

